\title{
Overview of Boundary Layer Transition Research in Support of Orbiter Return To Flight
}

\author{
Scott A. Berry ${ }^{*}$, Thomas J. Horvath ${ }^{*}$, and Francis A. Greene", \\ NASA Langley Research Center, Hampton, VA, 23681 \\ Gerald R. Kinder ${ }^{\dagger}$ \\ The Boeing Company, Huntington Beach, CA, 92647 \\ and \\ K. C. Wang ${ }^{\ddagger}$ \\ The Boeing Company, Houston, TX, 77059
}

\begin{abstract}
$\underline{\text { Abstract }}$
A predictive tool for estimating the onset of boundary layer transition resulting from damage to and/or repair of the thermal protection system was developed in support of Shuttle Return to Flight. The boundary layer transition tool is part of a suite of tools that analyze the aerothermodynamic environment to the local thermal protection system to allow informed disposition of damage for making recommendations to fly as is or to repair. Using mission specific trajectory information and details of each damage site or repair, the expected time (and thus Mach number) at transition onset is predicted to help define the aerothermodynamic environment to use in the subsequent thermal and stress analysis of the local thermal protection system and structure. The boundary layer transition criteria utilized for the tool was developed from ground-based measurements to account for the effect of both protuberances and cavities and has been calibrated against select flight data. Computed local boundary layer edge conditions were used to correlate the results, specifically the momentum thickness Reynolds number over the edge Mach number and the boundary layer thickness. For the initial Return to Flight mission, STS-114, empirical curve coefficients of 27, 100, and 900 were selected to predict transition onset for protuberances based on height, and cavities based on depth and length, respectively.
\end{abstract}

\section{$\underline{\text { Nomenclature }}$}

C empirical curve coefficient

M Mach number

Re unit Reynolds number $(1 / \mathrm{ft})$

$\operatorname{Re}_{\mathrm{L}} \quad$ length Reynolds number based on $\mathrm{L}$

$\mathrm{p} \quad$ pressure (psi)

$\mathrm{T}$ temperature $\left({ }^{\circ} \mathrm{R}\right)$

$\mathrm{X} \quad$ longitudinal distance from the nose (in)

$\mathrm{L}_{\text {Ref }} \quad$ model reference length from nose to body-flap hinge line $(9.7 \mathrm{in})$

$\mathrm{k} \quad$ roughness protuberance height (in)

$\mathrm{K}_{\mathrm{EQ}} \quad$ equivalent roughness height from distributed TPS steps and gaps (in)

L,W,D cavity dimensions, length, width, and depth (in)

\footnotetext{
* Aerospace Engineer, Aerothermodynamics Branch, Research and Technology Directorate.

$\dagger$ Entry Aeroheating Analyst, Thermal Systems, MC H012-C248.

$\vdash$ Engineer/Scientist 5, Integrated Defense Systems.
} 


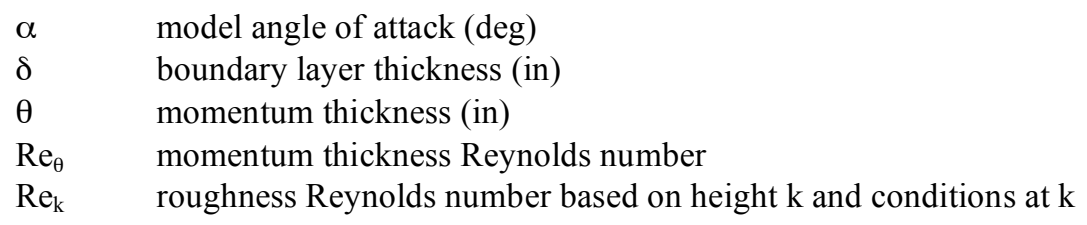

\begin{tabular}{|c|c|}
\hline Sub & \\
\hline$\infty$ & freestream static conditions \\
\hline $\mathrm{t} 1$ & reservoir conditions \\
\hline $\mathrm{t} 2$ & stagnation conditions behind normal shock \\
\hline e & local edge condition \\
\hline aw & adiabatic wall \\
\hline $\mathrm{w}$ & model surface \\
\hline $\operatorname{tr}$ & transition onset \\
\hline inc & incipient \\
\hline eff & effective \\
\hline
\end{tabular}

\section{$\underline{\text { Introduction }}$}

In support of the Shuttle Orbiter Return-To-Flight (RTF) program, a team of researchers was assembled to develop a predictive tool for estimating boundary layer transition (BLT) onset from thermal protection system (TPS) damage. The BLT Tool calculates the expected time of boundary layer transition during entry based on observed damage (and/or repair) locations and geometries. The tool includes a database of computed boundary layer parameters that cover a range of nominal trajectories for entry and utilizes an interpolation tool to extract specific local properties for determining the boundary layer state during the mission trajectory. Within a year, this analytic tool was provided to the program. The BLT Tool supports the process of evaluating TPS damage in order to determine if the Orbiter vehicle is safe to fly as-is, or a repair or safe haven to the International Space Station (ISS) is recommended. The BLT Tool is part of the Integrated Aeroheating Analysis Tools, ${ }^{1}$ as an initial step in assessing which heating environment should be used in subsequent analyses.

The BLT Tool requires mission entry trajectory data (altitude, velocity, angle of attack, yaw, air density, air temperature, etc.) to determine the local boundary layer parameters at each critical damage site. The program is a Fortran code and can be run on most computer systems. The present boundary layer transition methodology was newly developed based on simplified tripping elements and cavities on scaled wind tunnel models. ${ }^{2}$ A database of computational solutions at wind tunnel and flight conditions was generated to develop and apply the BLT correlation. ${ }^{3}$ Calibration of the BLT Tool has been carried out by comparison of predicted transition results to several of the historical high Mach number flight cases. ${ }^{4}$ Due to the limited scope of the historical flight data, in particular the lack of detailed cavity and gap filler information prior to entry into the earth's atmosphere, a larger uncertainty was placed on this tool until detailed results were obtained during subsequent RTF missions. ${ }^{5}$

The present paper provides an overview of the integrated effort that was involved with developing, maturing, and certifying the BLT Tool for estimating transition onset for the Orbiter program and is intended as part of a series of six papers on boundary layer transition research in support of RTF. The following references are the five companion papers. Reference 1 provides an introduction to the relevant aeroheating issues for RTF, the new aeroheating tools developed, and the analysis process used during the first RTF mission, STS-114. Reference 2 reviews the experimental databases that were developed to support the BLT Tool for RTF, and provides details on the experimental analysis and resulting correlations. Reference 3 discusses the boundary layer properties interpolation tool and the supporting computational databases developed for both the BLT and Cavity Heating Tool (see Ref. 1 for a discussion of other tools). Reference 4 reviews the historical Orbiter flight data, describes the methodology established to thoroughly collect the historical damage information, and provides the analysis of several of the flight cases used to calibrate the BLT Tool. And lastly, Ref. 5 describes how the BLT Tool was used during STS-114 and provides a comparison of the predicted transition onset times from measured mission damage using the BLT Tool to the measured flight transition data as an initial attempt to validate the tool. 


\section{$\underline{\text { RTF Requirement for On-Orbit Assessment }}$}

The Shuttle program has an existing roughness criterion, which is used primarily to assess vehicle TPS processing and readiness for flight. ${ }^{6}$ Figure 1 provides the existing Orbiter roughness map that is used to specify the pre-flight allowable roughness requirements by zones. An equivalent roughness $\left(\mathrm{K}_{\mathrm{EQ}}\right)$ method accounts for TPS tile steps and gaps, ${ }^{7}$ within each zone, for instance in Zone 3 the allowable pre-flight normalized $\mathrm{K}_{\mathrm{EQ}}$ is approximately 0.11 -in. ${ }^{8}$ Unfortunately, this approach was never intended for use during missions to assess damage to the outer mold lines (OML). Tile damages and subsequent repairs represent a

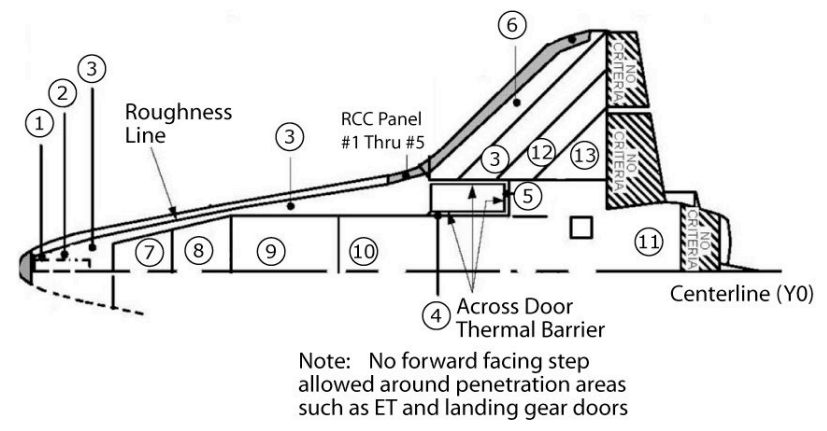

Figure 1. Existing Orbiter allowable roughness zones significant deviation from the applicability of the existing $\mathrm{K}_{\mathrm{EQ}}$ framework. A new predictive tool for estimating boundary layer transition onset from OML damage and/or repair was required to allow analysis of TPS health during future missions.

The Columbia accident investigation ${ }^{9}$ identified the need for a capability to repair damage to the Orbiter TPS. Damage to the OML can occur during launch or even micro-meteor orbital debris (MMOD). Onorbit inspections are now a part of future mission profiles to observe and document the OML condition prior to entry. Once the surface condition is determined, a repair criterion is needed to determine which sites are acceptable as-is and which require repair. The Shuttle program is investigating many repair scenarios. An early repair concept for the acreage tiles was to fill in the damage sites (cavities) with STA-54, ${ }^{1}$ a silicon-based material that is likely to swell and ablate under reentry conditions. Thus, the surface condition during entry may consist of cavities and/or protruding gap fillers from un-repaired damage, protuberances from repairs, and ablation products and out-gassing from the sites repaired with STA-54. The existing roughness criteria for the Shuttle program is not able to quantify the local and global effects of a damaged OML, and in particular determine the expected transition time for subsequent aeroheating analyses of the TPS and structure prior to entry. Note that recently the Orbiter program has eliminated the STA-54 repair concept.

References 10-20 provide just a few of the relevant reports on the subject of roughness induced boundary layer transition at hypersonic speeds, establishing the starting point for the present effort. A sizeable research team was formed to develop a new BLT prediction tool for RTF. Engineers with the corporate knowledge of Shuttle vehicle and measurement systems were assigned to examine and review the historical flight information. Experimentalists were tasked with the development of new wind tunnel databases of boundary layer transition effects from cavities, protuberances and ablation. Computational experts were responsible for the calculation of the boundary layer parameters used to correlate the experimental results and extrapolate to flight. Finally, the BLT correlations were calibrated against a limited set of flight cases, and then the tool was developed and certified by the Orbiter program to support RTF. The separate elements associated with the BLT Task, as discussed above, are shown graphically in Fig. 2. Due to the relative lack of high quality boundary layer transition data from flight (to be discussed subsequently), the wind tunnel derived correlations were used to establish the final BLT Tool empirical curve coefficients (C) in combination with the limited flight calibration cases.

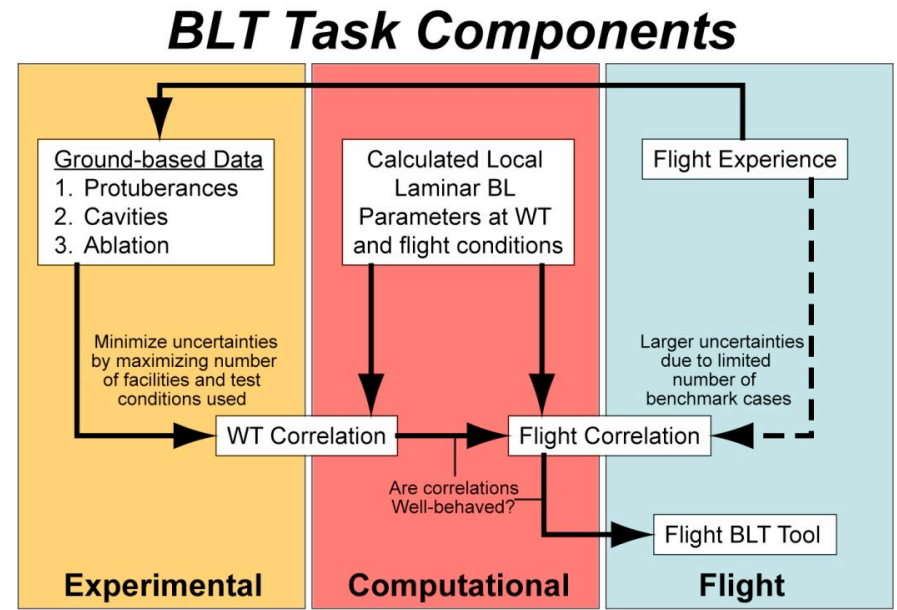

Figure 2. Critical elements for development of new BLT Tool for on-orbit assessments 
As noted in Ref. 20, transition correlations typically take the form shown in Fig. 3, where the results are plotted in log-log coordinates and if the data fall along a straight line curve with a 45-deg slope (exponent $n=-1$ ), then the transition parameter multiplied by the disturbance parameter is equal to a constant. Note that to the left of the curve, the disturbance has no effect; while to the right the disturbance behaves as a fully effective trip (turbulent immediately behind the disturbance source). Typically, the transition process is characterized by a zone, but for the sake of simplicity is represented here with a line. This ideal situation allows the use of a simple relation to predict the effect of a measured roughness dimension on

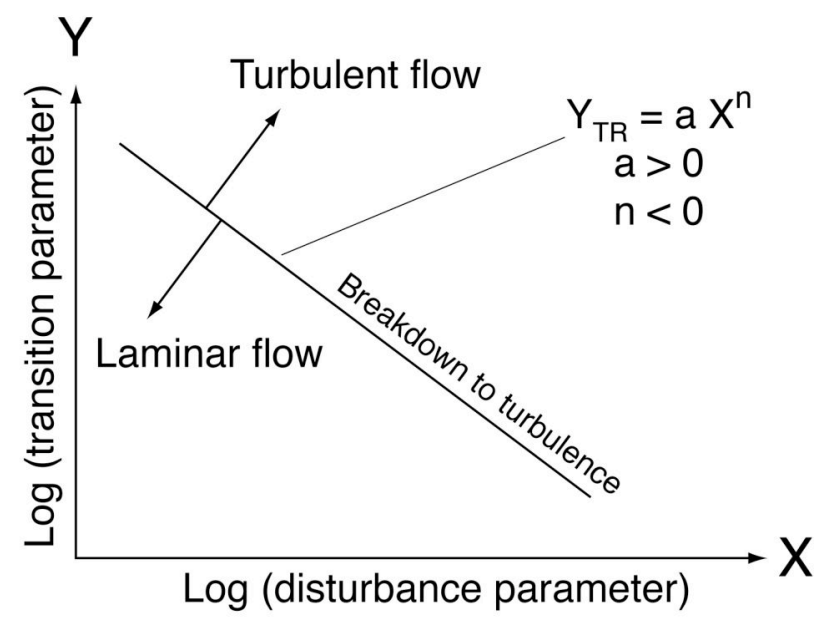

Figure 3. Generalized approach for boundary layer transition correlation development (Ref. 20) transition using computed boundary layer properties. The choice of computational method is at the discretion of the researcher, as long as reliable results are obtained and that the method (code and edge definition) is applied consistently with the way that the correlation was developed, along with a healthy appreciation of the limitations of the numerical method. A comparison of the advantages and disadvantages between the simpler engineering-type computational methods and the higher fidelity computational fluid dynamics (CFD) methods led to the selection of an engineering-type code, LATCH (Ref. 21), to provide the boundary layer parameters for the initial correlation. While LATCH provides only the edge parameters, it is relatively quick and proven. As noted in Ref. 11, the boundary layer edge parameters from LATCH were sufficient to develop a useable correlation based on the momentum thickness Reynolds number $\left(\operatorname{Re}_{\theta}\right)$ over edge Mach number $\left(M_{e}\right)$ and the boundary layer thickness $(\delta)$. On the other hand, benchmark CFD codes such as LAURA (Ref. 22) provide additional information within the boundary layer, but at the expense of increased computational time and uncertainties associated with grid resolution affecting the boundary layer edge location. Boundary layer profiles would be required to investigate the use of the roughness Reynolds number $\left(\operatorname{Re}_{\mathrm{k}}\right)$ approach (suggested in Ref. 20). Given the time constraints for computing the number of solutions required to populate both the wind tunnel and flight database, the decision was made to use the engineering approach to generate the initial correlation and then to investigate the higher-fidelity results at a later time.

From Ref. 11, a comparison of Orbiter, X-33 (taken from Ref. 23), and X-38 (Ref. 24) boundary layer transition correlations based on edge conditions and fully effective results is shown in Fig. 4 . Note that all

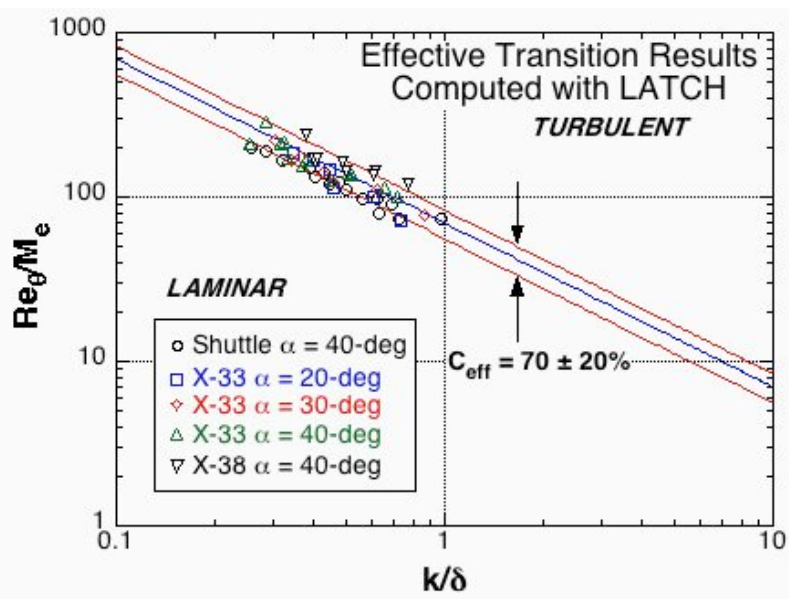

Figure 4. Comparison of existing lifting-body transition data with protuberances the data fall within $20 \%$ of a straight line curve coefficient of $\mathrm{C}=70$, based on using $\mathrm{Re}_{\theta} / \mathrm{M}_{\mathrm{e}}$ as the transition parameter and $\mathrm{k} / \delta$ as the disturbance parameter. These results suggest that as long as a consistent method is used, and in these cases the facility, test technique and computational approaches were the same, the resulting boundary layer transition correlation appears universally applicable for different lifting-body configurations, angles of attack, and locations on the body. While the existing Orbiter transition results were sufficient to show the agreement with the other databases, additional data were required for the current effort. New experimental results on the Orbiter were required for protuberances, cavities, and ablation over as 
wide a range of simulation parameters as possible $\left(\alpha, \mathrm{M}_{\infty}, \mathrm{Re}_{\infty}, \mathrm{T}_{\mathrm{W}}\right.$, etc.). For protuberances, additional data along the wing leading edge and for a range of angles of attack were required. For cavities and localized ablation, no existing data were available, so any results that can be used to investigate transition correlations were desirable.

\section{BLT Task Development}

The RTF BLT Task was initiated in December 2003 after the completion of the accident investigation. Due to the fast paced nature of the RTF effort, resources (manpower, tunnel time, computational support, etc.) were scoped, identified, and negotiated with the RTF Program prior to the development of detailed roadmaps. Schedule constraints dictated completion of the task prior to STS-114 (the first RTF mission), which at the time was expected to launch at the end of FY04. Therefore, the roadmap and approach that was developed at the beginning was dictated by the initial resource and schedule constraints. In hindsight, knowing the additional time that would be available to complete the task due to eventual delay of the launch of STS-114 from October 2004 to July 2005, a different approach might have been adopted (for instance the use of CFD solutions instead of LATCH). Nevertheless, a rough order of magnitude effort was scoped out for each of the sub-task elements (experimental, computational, and flight) based on the initial resource estimates.

For the experimental element, an initial round of testing was planned for the hypersonic facilities of NASA Langley Research Center (LaRC), shown in Fig. 5. Ten weeks of allotted tunnel time were divided between the protuberance ( 5 occupancy weeks within the three LaRC facilities), cavity ( 3 weeks, two facilities), and ablation ( 2 weeks, one facility) testing. For protuberances, the plan was to populate a database comprised of several locations along the windward surface, both on the centerline and attachment lines, multiple heights, and for a range of angle of attacks. For cavities, a database comprised mainly of simplified cavities of multiple lengths, depths and widths on centerline at $\mathrm{x} / \mathrm{L}=0.3$ for two angles of attack was proposed. For ablation, an initial screening study to investigate model construction issues associated with the blowing apparatus was proposed. The blowing results were restricted to the same location utilized for the cavity testing.

For the computational element, the LaRC in-house engineering computational capability, the LATCH code, was chosen due to the large number of wind tunnel and flight solutions required and the time constraint of less than a year to complete the tool. To develop the wind tunnel correlation of the boundary layer results, nearly four-dozen computational solutions were required to cover the three LaRC facilities, multiple angles of attack, and the range of Reynolds numbers. Additionally, there was an existing protuberance database previously obtained in the Arnold Engineering and Development Center (AEDC) Tunnel B on a $1.8 \%$ Orbiter model (from 1996) ${ }^{25,26}$ that required another two-dozen solutions (angles of

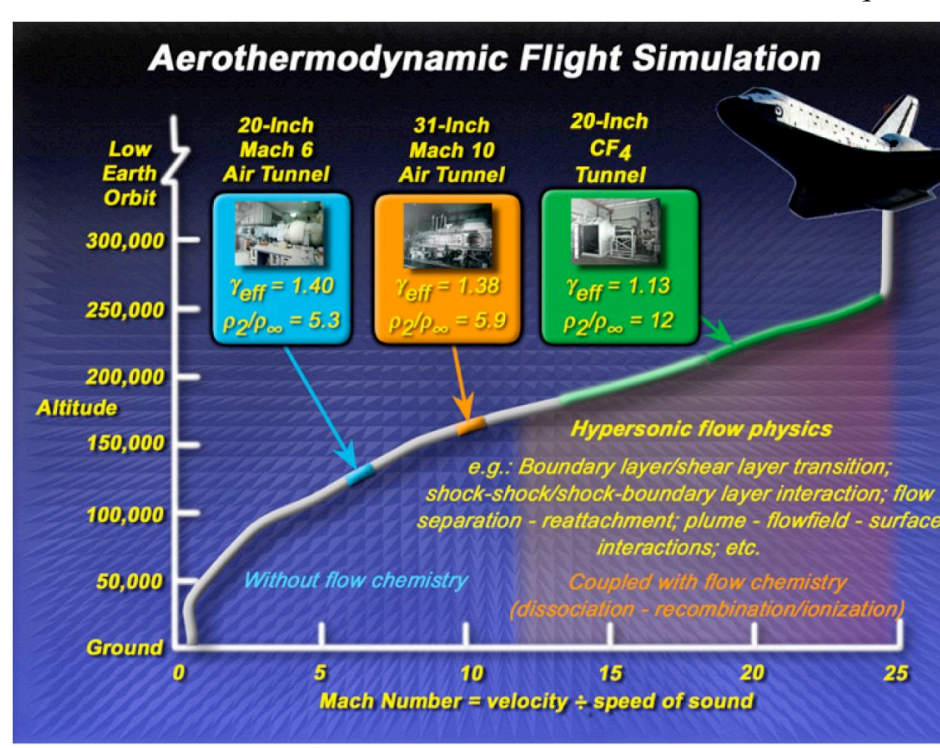

Figure 5. Aerothermodynamic flight simulation within the LaRC facilities attack of 35 and 40-deg, and multiple Reynolds numbers under both warm and cold wall model conditions), as well as the potential for additional BLT data from an upcoming test in the CUBRC LENS facility in Buffalo, NY (Ref 27 provides preliminary information on this effort). Once a satisfactory roughness correlation was developed, then additional solutions would be required at flight conditions (perhaps another 30 or so calculations across the Mach number, angle of attack, and Reynolds number range associated with a typical trajectory). On a time available basis, CFD solutions would be examined to see if eventual migration to using fully viscous solutions for the correlation was reasonable. 
For the flight element, a complete reanalysis of the existing flight data from the perspective of boundary layer transition was warranted. To date there has been 114 flights of the Shuttle Transportation System over the past 25 years. The engineers closest to the Shuttle program and vehicle hardware were tasked with sifting through the data from the past flights. A few of the previous attempts at analyzing the flight data are reported in Refs. 7, 28, and 29. As noted in Ref. 25, the majority of the early flight transition times have been the result of the TPS gap fillers sticking out (protuberances). However, since the new BLT Tool is intended to disposition both protuberances and cavities, the existing data will need to be examined again in hopes of providing credible cavity transition data.

\section{Status and Results}

\section{Protuberances}

New protuberance data ${ }^{30}$ were acquired from three hypersonic facilities at LaRC: the 20-In Mach 6 Tunnel, the 31-In Mach 10 Tunnel, and the 20-In $\mathrm{CF}_{4}$ Tunnel. The initial position going into this activity was to utilize the correlation methodology previously identified in Fig. 4 with $\mathrm{Re}_{\theta} / \mathrm{M}_{\mathrm{e}}$ as the transition parameter and $\mathrm{k} / \delta$ as the disturbance parameter pending any new data from the different facilities. As noted, the simplicity of this approach is that if the data falls along the straight line represented by $\left(\mathrm{Re}_{\theta} / \mathrm{M}_{\mathrm{e}}\right)(\mathrm{k} / \delta)=\mathrm{C}$, where $\mathrm{C}$ is a constant, then there is a direct link between the disturbance height, $\mathrm{k}$, and the expected transition behavior. Indeed, as the new data was obtained, all three facilities showed this behavior, however the curve coefficients (C) were not consistent between each facility. A modified approach using a temperature ratio correction along with the momentum thickness (instead of the boundary layer thickness) as the disturbance parameter, as shown in Fig. 6, was found to essentially collapse all three datasets (as well as most of the AEDC data) into a single correlation. However, when this new approach was applied to the existing flight calibration cases (to be discussed later) inconsistent results were obtained. In fact, it was found that the original approach using the curve coefficient from the 20-In Mach 6 Tunnel provided the best results in predicting transition onset for the flight cases. These findings were presented to the Orbiter program for review and eventually a curve coefficient of 27 using the original approach was adopted to conservatively capture, with 95\% confidence, transition onset (also referred to as incipient) for all the Mach 6 and flight data, shown in Fig 7. Reference 2 provides additional details of the protuberance experimental data analysis and correlation results obtained in support of the BLT Task for RTF.

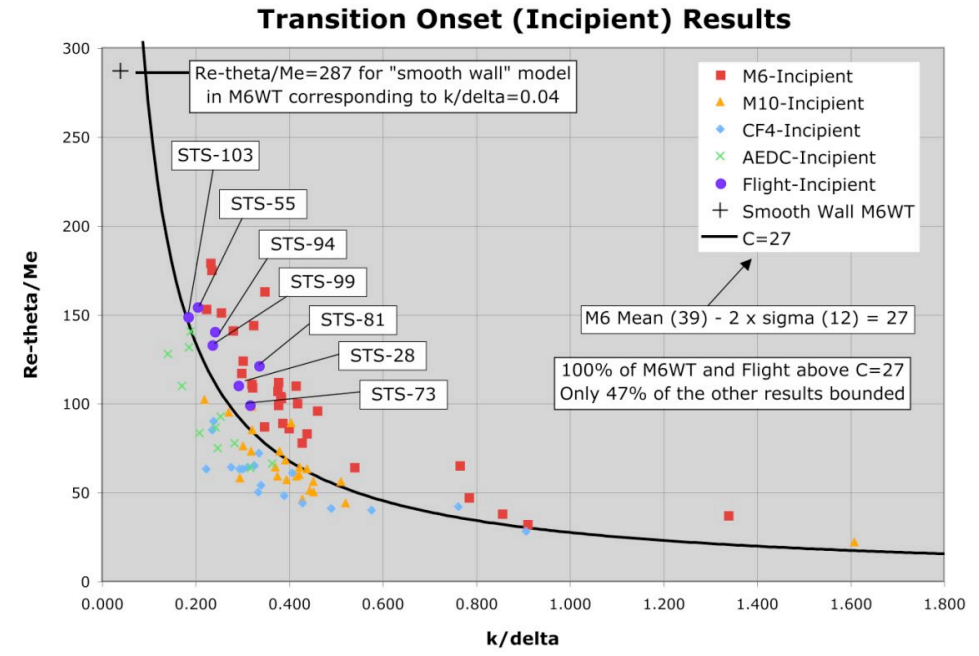

Figure 7. Protuberance correlation used for STS-114 


\section{Cavities}

Cavity transition data ${ }^{31}$ was also newly acquired from all three hypersonic facilities at LaRC: the 20-In Mach 6, the 31-In Mach 10, and the 20-In $\mathrm{CF}_{4}$ tunnels. The hope going into the cavity testing was that the new data would support the continued use of the protuberance methodology previously discussed with some simple modification to account for the cavity dimensions (some unknown combination of the cavity depth, length, and width). The initial round of cavity testing was focused on idealized rectangular "shoebox" cavities at a single location in order to adequately cover the parametrics in cavity dimensions, as shown in Fig. 8. Fifteen models were manufactured with cavities on the model centerline at $x / L_{\text {Ref }}=0.3$, with variations in the cavity length $(\mathrm{L})$, width $(\mathrm{W})$, and depth (D) to cover expected ranges of cavity $\mathrm{L} / \mathrm{D}, \mathrm{D} / \delta$, and W/D for flight. ${ }^{2}$

As would be expected, the data indicates that a cavity of a given depth is less effective at promoting transition than a protuberance of equivalent height and that increasing any of the cavity's dimensions would promote transition quicker. However, attempts at casting the cavity results within the protuberance framework using an empirical formulation using all three cavity dimensions in lieu of $k$ were unsuccessful leading up to STS-114. Using the protuberance correlation for cavities will result in an overly conservative prediction on transition onset. Based on the present experimental data, cavities with L/D less than 20 and more than half the tile thickness remaining is not likely to force transition earlier than Mach 18 over most of the windward surface (long and deep cavities not probable based on a historical flight data review). The main area of concern is the Orbiter nose region, where the boundary layer is thinner, thus detailed cavity dimensions will be required to properly disposition these sites. Based on the review by the Orbiter program, the protuberance BLT correlation methodology was adopted with an appropriate factor applied to account for an independent assessment of either the length or depth of the cavity sites. For instance, based on the limited flight cavity calibration cases, a curve coefficient of 100 will be used for STS-114 based on cavity depth and 900 based on cavity length, as shown in Fig. 9. See Ref. 2 for complete details.
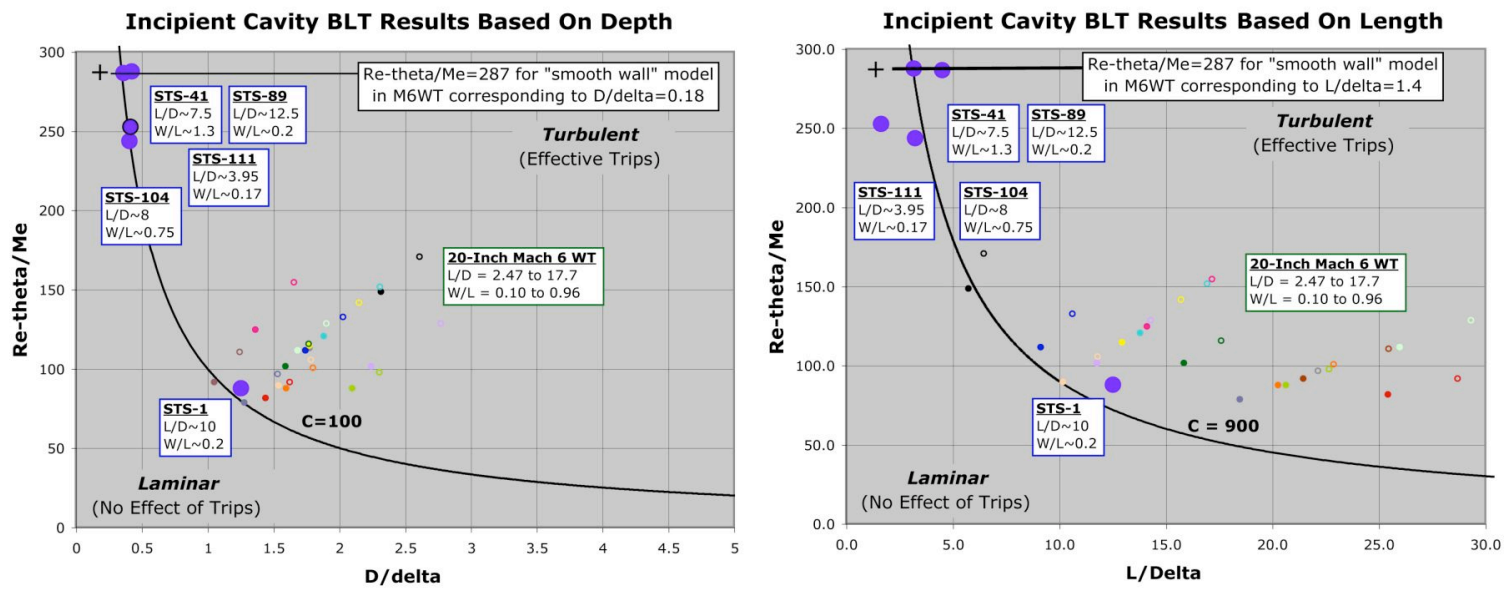

Figure 9. Cavity correlations used for STS-114 


\section{Ablation}

Boundary layer transition data due to ablation were also newly acquired for the present RTF effort but only from the LaRC 20-In Mach 6 Tunnel. A screening study was initiated to assess testing technique capabilities to investigate transition behavior with mass addition to the boundary layer from a smalllocalized repair site. As with the new cavity data, this initial assessment was conducted with the damage site being limited to a single location (on centerline at $\mathrm{x} / \mathrm{L}=0.3$ ). These results successfully demonstrated the ability to fabricate rapid-prototyped resin models with internal passages for providing local blowing to the windward surface. The test results indicated that local blowing could promote transition earlier than would be otherwise expected. However, when the wind tunnel results are compared against the estimated in-flight ablation rates expected from STA-54, as shown in Fig. 10, the blowing rates required to affect transition onset are an order of magnitude higher. Additionally, when heavier molecular weight gases (identified in Fig. 10 by $\mathrm{CF}_{4}$ ), more representative of the out-gassing constituents of STA-54, were used in lieu of air for blowing through the ablation patch, transition onset was delayed. The initial assessment was that ablation should not be a first order effect that needed to be accounted for with the initial version of the BLT Tool. Since the time of these tests, STA-54 has been removed as a repair option. See Ref. 2 for a more detailed description of these results.

\section{Computational Database}

To support the BLT Task, computational solutions at both wind tunnel and flight conditions were required. The wind tunnel solutions were used to investigate and generate the BLT correlation, while the flight solutions provide the means with which to extrapolate the ground-based correlation to flight. With the large number of flight solutions required to cover a typical Shuttle trajectory, a new boundary layer properties interpolation tool (BLPROP) was generated to minimize the number of flight solutions and to automate the process of obtaining the necessary flow properties at the boundary layer edge. Figure 11 provides a plot of the solutions required to cover typical Shuttle trajectories as a function of Mach number and angle of attack. The Shuttle Operational Data Book $^{32}$ and previous Orbiter flight trajectories were used to define the bounds of the solution database. The 30 solution cases shown, which represent the computational database, were first computed with inviscid LAURA ${ }^{22}$ solutions and then coupled with $\mathrm{LATCH}^{21}$ to determine the boundary layer properties. The LATCH code does not account for non-equilibrium

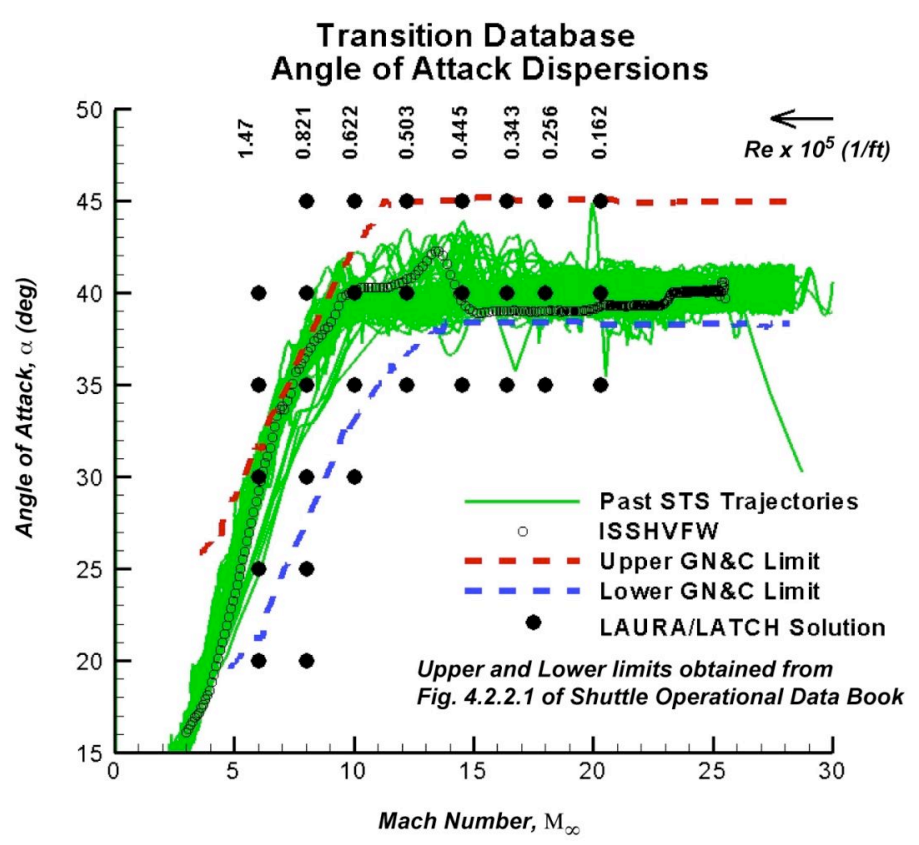

Figure 11. Computational database interpolation tool 
gas effects, thus the initial computational database range was restricted from Mach 6 to 20. Previous flight experience with early boundary layer transition (to be discussed subsequently) suggested that this range would be sufficient for the BLT Tool. The BLPROP database tool interpolates both spatially within the solution grid to obtain the local properties at each damage or repair site of interest, then interpolates temporally within the solution database to provide the boundary layer properties along the trajectory. Reference 3 provides a more detailed description of the BLPROP Tool and the solutions used to generate the boundary layer transition results for RTF.

\section{Flight Database}

A review of the historical flight data from the perspective of boundary layer transition was initiated in support of the present effort. With over 100 flights to review, the strategy was to start with the flights that had the earliest transition times, or highest Mach numbers at the time of transition, and then work towards the later times. Initial review of the historical data suggests that most early transition events are due to protruding gap fillers as identified from the post-flight runway observations. For instance, the three flights with the earliest transition times (BLT onset times earlier than $1000 \mathrm{sec}$ after entry interface), STS-28, 73, and 103, all appear to be due to gap fillers that were measured on the runway as protruding from the OML between 0.25 to 0.6 -in. Figure 12 provides an example result of the BLT and wedge tools (see Ref. 4 for a discussion on the wedge tool) analysis for STS-28 (a composite plot indicating the transition onset times as measured from the surface thermocouples, the locations of the major documented OML damage, and the resulting turbulent wedge that would result). As detailed in Ref. 4 , the primary candidates for the measured early transition for this flight were three 0.5 -in protruding gap fillers on the windward surface. The gap filler identified as $\mathrm{A}$ in the figure is the only one that could have affected the aft surface thermocouple, which revealed transition onset to be at 902 seconds (Mach 18). This flight, along with other high Mach number transition flights, were the initial cases used to calibrate the BLT Tool. In total, there were 7 early transition cases identified and used for calibration of the

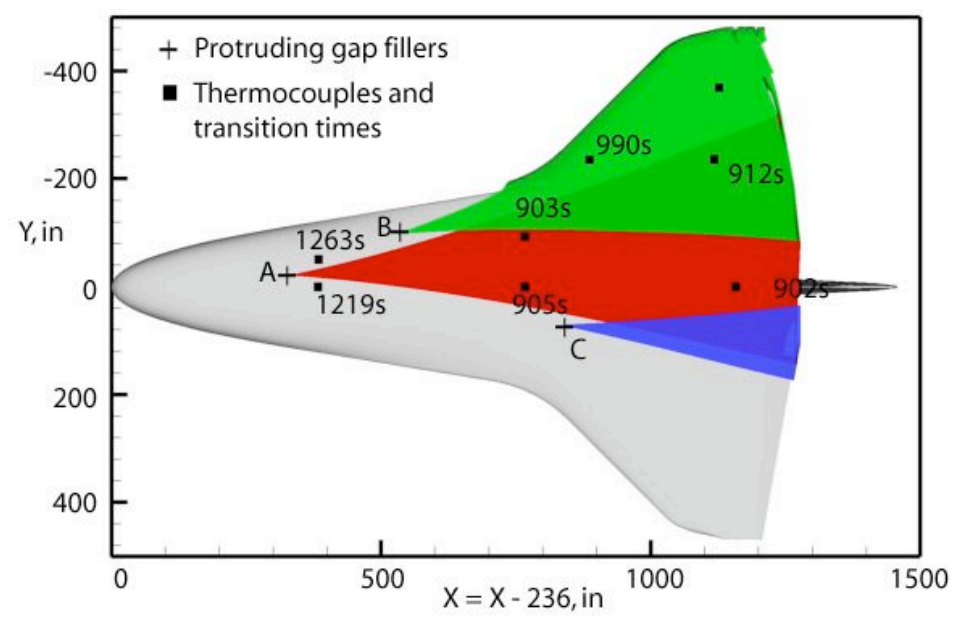

Figure 12. Example of the historical flight transition analysis with the BLT and wedge tools on STS-28 protuberance correlation: STS-28, 55, 73, 81, 94, 99, and 103 (and these are identified in Fig. 7). From the initial review of the historical data, only five flights had been identified as possibly having cavity-induced transition: STS-1, 41, 89, 104, and 111 (identified in Fig. 9). However, the initial historical review and analysis of these calibration flights prior to STS-114 was based on a quick examination of readily available sources of damage information. Since that time, access to additional damage data has revealed that some of these assumed cavity cases may have had gap fillers protruding, but not clearly identified in the documentation. Reference 4 provides a more thorough description of the flight data analysis that was initiated post-STS-114 to better establish our understanding of the root causes of these critical calibration cases.

\section{BLT Tool Summary}

The BLT Tool for prediction of transition onset was developed for use by the Shuttle program. A conceptual flowchart of the BLT Tool analysis process is shown in Fig. 14. BLT Prediction is based on mission specific trajectory and damage/repair (either cavity or protuberance) information that will allow informed disposition of the damage sites, with the potential to reduce the necessity for unnecessary and risky extravehicular activity (EVA). The output of the tool is a determination of the predicted transition onset times for each damage site, which then allows a selection of one of the pre-flight developed aeroheating environments for use with the subsequent analyses (see Ref. 1). 
Flight Phase Support: The BLT Tool can be used pre-launch to assess flight trajectories with nominal roughness, in orbit to assist in damage disposition analysis, and for entry to predict transition onset times for locating airborne infrared (IR) measurement assets (NASA WB-57 aircraft, see Ref. 5).

Operational Requirements: The Fortran program requires mission entry trajectory data (altitude, velocity, angle of attack, yaw, air density, air temperature, etc.) and damage site locations and dimensions to determine the local boundary layer parameters used for predicting transition onset for each damage site. A companion tool, called the wedge tool (see Ref. 4), is used to predict the zone of influence behind each damage/repair site, thus providing the potential interactions between the various damage sites.

Limitations \& Uncertainties: The computational approach is presently limited to between Mach 6 and 20. The computational database for flight is additionally limited to the angle of attack bounds identified in the Shuttle Operational Data Book. The use of this tool outside of these limits should be done with caution. The updated boundary layer transition methodology is based on scaled wind tunnel models and has only been partially compared to flight data with the highest Mach number at the time of transition onset of 18 . Due to the limited scope of the historical flight data in regards to detailed cavity and gap filler information prior to entry, a larger uncertainty should be placed on this process until detailed and calibrated results are obtained in up-coming flights.

\section{Summary}

The present paper provides an overview of several studies that were integrated to develop a predictive tool, in support of the Shuttle RTF effort, for estimating the onset of boundary layer transition from major deviations to the OML. The BLT Tool is one of the initial steps in the analysis process of the local TPS aerothermodynamics in order to allow informed disposition of damage for making recommendations to fly as is or to repair. Using mission specific trajectory information and details of each damage site or repair, the expected time of transition is predicted to define the proper aerothermodynamic environment to use in the subsequent thermal and stress analysis of the structure. The BLT criteria utilized for the tool were developed from ground-based measurements to account for the effect of both protuberances and cavities and have been partially calibrated against flight data. Using boundary layer edge conditions to correlate the results, specifically the momentum thickness Reynolds number over the edge Mach number and the boundary layer thickness, curve coefficients of 27, 100, and 900 were adopted to conservatively predict transition onset for protuberances based on height, and cavities based on depth and length, respectively. Additionally, the effect of a localized ablator was experimentally examined as part of this effort. A comparison of the blowing rates required to promote early transition in the tunnel was found to be over a order of magnitude higher than the expected blowing rates for the repair material at flight conditions.

\section{Acknowledgements}

The remainder of the BLT Team should also be recognized for their contributions to the present body of work: Ron Merski, Derek Liechty, Karen Bibb, Greg Buck, Harris Hamilton, Jim Weilmuenster, Chuck Campbell, Stan Bouslog, Ben Kirk, Gary Bourland, Amy Cassady, Dan Reda, James Reuther, Dennis Chao, Brian Anderson, Jay Hyatt, Maria Barnwell, Steve Schneider, Rudy King, Mike Kegerise, and Cathy McGinley. Many thanks for a job well done! 


\section{$\underline{\text { References }}$}

${ }^{1}$ Campbell, C. H., Anderson, B., Bourland, G., Bouslog, S. A., Cassady, A. M., Horvath, T. J., Berry, S. A., Gnoffo, P. A., Wood, W. A., Reuther, J., Driver. D., Chao, D., Hyatt, A.J., and Picetti, D., "Orbiter Return To Flight Entry Aeroheating," AIAA-2006-2917, June 2006.

${ }^{2}$ Horvath, T. J., Berry, S. A., Merski, N. R., Berger, K. T., Liechty, D. S., Buck, G. M., and Schneider, S. P., "Shuttle Damage/Repair From the Perspective of Hypersonic Boundary Layer Transition - Experimental Results," AIAA-2006-2918, June 2006.

${ }^{3}$ Greene, F. A., and Hamilton, H., "Development of a Boundary Layer Properties Interpolation Tool in Support of Orbiter Return-To-Flight,” AIAA-2006-2920, June 2006.

${ }^{4}$ McGinley, C., Berry, S. A., Kinder, G. R., Barnwell, M., Wang, K. C., and Kirk, B. S., "Review of Orbiter Flight Boundary Layer Transition Data,” AIAA-2006-2921, June 2006.

${ }^{5}$ Berry, S. A., Horvath, T. J., Cassady, A. M., Kirk, B. S., Wang, K.C., and Hyatt, A. J., "Boundary Layer Transition Results From STS-114,” AIAA-2006-2922, June 2006.

6 Haney, J. W., “Orbiter (Pre STS-1) Aeroheating Design Data Base Development Methodology: Comparison of Wind Tunnel and Flight Test Data," NASA CP-3248, Orbiter Experiments (OEX) Aerothermodynamics Symposium, April 1995, pp. 607-675.

${ }^{7}$ Bouslog, S. A., An, M. Y., and Derry, S. M., "Orbiter Windward Surface Boundary Layer Transition Flight Data," NASA CP-3248, Orbiter Experiments (OEX) Aerothermodynamics Symposium, April 1995, pp. 703-739.

${ }^{8}$ Goodrich, W. D., Derry, S. M., and Bertin, J. J., "Shuttle Orbiter Boundary Layer Transition at Flight and Wind Tunnel Conditions," Shuttle Performance: Lessons Learned, Part 2, NASA CP 2283, March 1983, pp. 753-779.

9 Columbia Accident Investigation Board Final Reports, Vols. I-VI [online resource], URL: http://caib.nasa.gov/ [cited Aug and Oct 2003].

${ }^{10}$ Berry, S. A., Bouslog, S. A., Brauckmann, G. J., and Caram, J. M., "Shuttle Orbiter Experimental Boundary-Layer Transition Results with Isolated Roughness," Journal of Spacecraft and Rockets, Vol. 35, No. 3, 1998, pp. 241-248.

11 Berry, S. A.; and Hamilton, H. H.: "Discrete Roughness Effects on Shuttle Orbiter at Mach 6," AIAA Paper 2002-2744, June 2002.

${ }^{12}$ Bouslog, S. A., An, M. Y., Campbell, C. H., Wang, K. C., and Pelley, R. L., "Orbiter Boundary-Layer Transition Working Group: Analysis and Ground Test Status Report," NASA Johnson Space Center, JSC-26812, Oct. 1994.

${ }^{13}$ Batt, R. G., and Legner, H. H., “A Review of Roughness-Induced Nosetip Transition,” AIAA J., Vol. 21, No. 1, Jan. 1983, pp.7-22.

${ }^{14}$ Van Driest, E. R., and Blummer, C. B., "Boundary Layer Transition on Cones and Spheres at Supersonic Speeds - Effects of Roughness and Cooling," U.S. Air Force Office of Scientific Research, Rept. $67-$ 2048, July 1967.

15 Berkowitz, A. M., Kyriss, C. L., and Martellucci, A., "Boundary Layer Transition Flight Test Observations," AIAA Paper 77-125, Jan. 1977.

${ }^{16}$ Boudreau, A. H., "Artificially Induced Boundary-Layer Transition on Blunt-Slender Cones at Hypersonic Speeds," Journal of Spacecraft and Rockets, Vol. 16, No. 4, 1979, pp. 245-251.

${ }^{17}$ Pate, S. R., "Dominance of Radiated Aerodynamic Noise on Boundary-Layer Transition in SupersonicHypersonic Wind Tunnels," Arnold Engineering Development Center, TR-77-107, Arnold Air Force Station, TN, March 1978.

18 Dirling, R. B. Jr., Swain, C. E., and Stokes, T. R., "The Effect of Transition and Boundary Layer Development on Hypersonic Reentry Shape Change," AIAA Paper 75-673, May 1975.

${ }^{19}$ Stetson, K. F., “Boundary-Layer Transition on Blunt Configurations," NASA Johnson Space Center, JSC26528, Feb. 1994. 
${ }^{20}$ Reda, D. C., "Review and Synthesis of Roughness-Dominated Transition Correlations for Reentry Applications," Journal of Spacecraft and Rockets, Vol. 39, No. 2, 2002, pp. 161-167.

${ }^{21}$ Hamilton, H. H. II, Greene, F. A., DeJarnette, F. R., "Approximate Method for Calculating Heating Rates on Three-Dimensional Vehicles," Journal of Spacecraft and Rockets, Vol. 31, No. 3, 1994, pp. 345-354.

${ }^{22}$ Gnoffo, P. A., "An Upwind-Biased, Point-Implicit Relaxation Algorithim for Viscous, Compressible Perfect-Gas Flow,” NASA TP-2953, Feb. 1990.

${ }^{23}$ Berry, S. A., Horvath, T. J., Hollis, B. R., Thompson, R. A., and Hamilton, H. H., "X-33 Hypersonic Boundary Layer Transition," Journal of Spacecraft and Rockets, Vol. 38, No. 5, 2001, pp. 646-657 (see also AIAA Paper 99-3560, June 1999).

${ }^{24}$ Horvath, T. J., Berry, S. A., Merski, N. R., Fitzgerald, S. M., "X-38 Experimental Aerothermodynamics," Journal of Spacecraft and Rockets, Vol. 41, No. 2, 2001, pp. 272-292 (see also AIAA Paper 2000-2685, June 2000).

${ }^{25}$ Bouslog, S. A., Bertin, J. J., Berry, S. A., and Caram, J. M., "Isolated Roughness Induced Boundary-Layer Transition: Shuttle Orbiter Ground Tests and Flight Experience," AIAA Paper 97-0274, Jan. 1997.

${ }^{26}$ Bertin, J. J., Stetson, K. F., Bouslog, S. A., and Caram, J. M., "Effect of Isolated Roughness Elements on Boundary-Layer Transition for Shuttle Orbiter," Journal of Spacecraft and Rockets, Vol. 34, No. 4, 1997, pp. 426-436.

${ }^{27}$ Smolinski, G. J., Hubner, J. P., and Holden, M. S., "Risk Mitigation Study for Instrumentation Layout Along Wing Leading Edge of a 1.8\%-Scale Space Shuttle Model Using TSP," AIAA 2005-478, Jan. 2005.

${ }^{28}$ Bertin, J. J., Hayden, T. E., and Goodrich, W. D., "Shuttle Boundary-Layer Transition Due to Distributed Roughness and Surface Cooling," Journal of Spacecraft and Rockets, Vol. 19, No. 5, 1982, pp. 389-396.

${ }^{29}$ Harthun, M. H., Blumer, C. B., and Miller, B. A., "Orbiter Windward Surface Entry Heating: Post-Orbital Flight Test Program Update," Shuttle Performance: Lessons Learned, Part 2, NASA CP 2283, March 1983, pp. 781-804.

${ }^{30}$ Liechty, D. S., Berry, S. A., and Horvath, T. J., "Shuttle Return To flight Experimental Results: Protuberance Effects on Boundary Layer Transition," NASA TM-2006-214306, May 2006.

${ }^{31}$ Liechty, D. S., Horvath, T. J., and Berry, S. A., "Shuttle Return To flight Experimental Results: Cavity Effects on Boundary Layer Transition,” NASA TM-2006-214305, May 2006.

${ }^{32}$ Shuttle Operational Data Book System, NSTS-08934 [online resource], URL https://opo.jsc.nasa.gov/sodw/ 